\title{
Erratum to: The Promotion of Self-Regulation Through Parenting Interventions
}

\author{
Matthew R. Sanders • Trevor G. Mazzucchelli
}

Published online: 13 September 2014

(c) Springer Science+Business Media New York 2014

\section{Erratum to: Clin Child Fam Psychol Rev DOI 10.1007/s10567-013-0129-z}

\section{Author's Statement of Conflict of Interest}

The Triple P-Positive Parenting Program is owned by the University of Queensland (UQ). The university, through its main technology transfer company UniQuest Pty Limited, has licensed Triple P International Pty Ltd to disseminate the program worldwide. Royalties stemming from this dissemination activity are distributed to the Parenting and Family Support Centre, School of Psychology, UQ; Faculty of Health and Behavioral Sciences at UQ; and contributory authors. No author has any share or ownership in Triple P International Pty Ltd. Matthew Sanders is the founder and an author on various Triple $\mathrm{P}$ programs and a consultant to Triple P International. Trevor Mazzucchelli is a trainer with Triple P International.

The online version of the original article can be found under doi:10.1007/s10567-013-0129-z.

M. R. Sanders $(\bowtie) \cdot$ T. G. Mazzucchelli

Parenting and Family Support Centre, The University of

Queensland, Brisbane, QLD 4072, Australia

e-mail: matts@psy.uq.edu.au; m.sanders@psy.uq.edu.au

T. G. Mazzucchelli

School of Psychology and Speech Pathology, Curtin University,

Bentley, Australia

e-mail: trevor.mazzucchelli@curtin.edu.au 